\title{
Emerging Gram-positive bacteria and drug resistance in cirrhosis patients with spontaneous bacterial peritonitis: A retrospective study
}

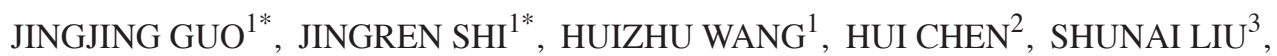 \\ JUNNAN $\mathrm{LI}^{4}$ and YAJIE WANG ${ }^{1}$
}

${ }^{1}$ Department of Clinical Laboratory, Beijing Ditan Hospital, Capital Medical University, Beijing 100015;

${ }^{2}$ School of Biomedical Engineering, Capital Medical University, Beijing 100069;

${ }^{3}$ Beijing Key Laboratory of Emerging Infectious Diseases, Institute of Infectious Diseases;

${ }^{4}$ Department of Research and Education, Beijing Ditan Hospital, Capital Medical University, Beijing 100015, P.R. China

Received August 2, 2018; Accepted March 21, 2019

DOI: $10.3892 /$ etm.2019.7502

\begin{abstract}
Spontaneous bacterial peritonitis (SBP) is one of the most severe complications in liver cirrhosis (LC) patients with ascites. The aim of the present study was to retrospectively analyze the bacterial spectrum and drug resistance in ascites culture of patients with SBP. A total of 3, 189 patients with ascites were enrolled in the present study, including 912 LC patients, of which 247 had SBP. It was revealed that in the 3, 189 patients, the ratio of SBP exhibited annual increases, especially in 2015, and this trend remained when cases were divided into two groups: Group A (admission, 2011-2013) and Group B (admission, 2014-2016). The 247 SBP patients were then stratified into two groups: Group 1 (admission, 2011-2013) and Group 2 (admission, 2014-2016). The rate of infection with gram-positive bacteria (GPB) was markedly higher in Group 2 compared with Group 1. Over time, GPB and gram-negative bacteria (GNB) were increased, while the increase of GPB was greater than that of GNB. Direct bilirubin and C-reactive protein levels, and the positive rate of ascites culture in Group 2 were greater than in Group 1. Furthermore, marked differences in serological and ascitic indexes or pathogeny, as well as complications between the patients with GPB and GNB
\end{abstract}

Correspondence to: Dr Yajie Wang, Department of Clinical Laboratory, Beijing Ditan Hospital, Capital Medical University, 8 Jing-Shun Dongjie, Chaoyang, Beijing 100015, P.R. China

E-mail:wangyajie@ccmu.edu.cn

*Contributed equally

Abbreviations: SBP, spontaneous bacterial peritonitis; LC, liver cirrhosis; CRP, C-reactive protein; PMN, polymorphonuclear neutrophil; GNB, Gram-negative bacteria; GPB, Gram-positive bacteria

Key words: spontaneous bacterial peritonitis, liver cirrhosis, bacterial spectrum, drug resistance infection were observed. The results regarding drug sensitivity revealed that the resistance rate of GPB and GNB to penicillin (ampicillin) was $100 \%$, while the resistance rate to amikacin, imipenem, meropenem and piperacillin/tazobactam was $0 \%$ for GNB, and similarly, the resistance rate to vancomycin, teicoplanin, amikacin and linezolid was $0 \%$ for GPB. The results suggested that combined use of ampicillin/sulbactam or piperacillin/tazobactam should be selected forempirical therapy. In cases of nosocomial infection, these drugs should be combined with vancomycin, linezolid or teicoplanin when required.

\section{Introduction}

Spontaneous bacterial peritonitis (SBP) is one of the common complications in liver cirrhosis (LC) patients with ascites (1). Several mechanisms contribute to the occurrence of SBP, including translocation of gut bacteria and their products, reduction of intestinal motility provoking bacterial overgrowth, alteration of the gut's barrier function and local immune responses (2). The occurrence of SBP in hospitalized ascites patients range from 10-30\% (3). Furthermore, SBP secondary to LC frequently aggravates liver damage and induces serious complications, including hepatorenal syndrome and hepatic encephalopathy (4). Therefore, early diagnosis and effective treatment are vital to improve the clinical outcome.

The clinical manifestations of SBP range from asymptomatic to typical peritoneal infection and even to severe hepatic encephalopathy or hepatorenal syndrome, easily leading to a missed diagnosis and misdiagnosis. Diagnostic puncture frequently has an important role in the diagnosis of SBP (5). In a previous study, the diagnosis was based on bacterial positive cultures in ascitic fluid and/or the testing of an elevated absolute fluid polymorphonuclear neutrophil (PMN) count in the ascites $\left(>250 / \mathrm{mm}^{3}\right)$ without any obvious abdominal intra-operatively detected source of infection (6).

In recent years, with the prevalence of multidrug-resistant bacteria and the re-distribution of the bacterial spectrum, SBP has become a serious clinical problem in several countries. In 
addition, a variation in the epidemiology of bacteria, which may be the reason for the increased prevalence of SBP, was reported in patients with long-term norfloxacin prophylaxis, appearing in the quinolone-resistant bacterial culture, as well as Gram-positive bacteria (GPB) (7). Numerous studies have focused on the therapeutic effects of various antibiotics and suggested that their efficacy is associated with SBP infection strains. A recent analysis determined that the rate of third-generation cephalosporin resistance ranged from 15.6-44.0\% in SBP cases (8). In conclusion, the selection of effective antibiotics according to the type of pathogen it is crucial for SBP patients.

The present study aimed to retrospectively examine changes in the bacterial spectrum, laboratory characteristics and drug resistance in LC patients with SBP. The results may contribute to the understanding of the etiologic features of SBP and may provide guidance for the selection of medication for empirical treatment.

\section{Materials and methods}

Subjects. A total of 3, 189 patients with ascites, including 912 LC patients, of which 247 had SBP, who had been admitted to Beijing Di Tan Hospital, Capital Medical University (Beijing, China) between January 2011 and December 2016 were retrospectively enrolled in the present study. Patients with ascites were assigned to Group A (admission, 2011-2013) and Group B (admission, 2014-2016). Patients with LC were assigned to Group A1 (admission, 2011-2013) and Group B1 (admission, 2014-2016). Of these, the patients with SBP identified by positive culture were assigned to Group 1 (admission, 2011-2013) and Group 2 (admission, 2014-2016).

All of the patient data were retrospectively retrieved from their electronic health records. The present study was approved by the Ethics Committee of the Beijing Di Tan Hospital (Beijing, China) and was in accordance with the 1975 Declaration of Helsinki.

According to the guidelines published by the American Association for the Study of Liver Diseases (9) and the European Association for the Study of the Liver (10), the diagnostic standard for SBP was a positive ascitic fluid culture and/or a polymorphonuclear leukocyte count of the ascitic fluid of $\geq 250$ cells $/ \mathrm{mm}^{3}$.

Laboratory techniques. The ascitic fluid $(10 \mathrm{ml})$ was collected and inoculated into aerobic and anaerobic blood bottles (BD Biosciences) and cultured at an automated culture system (BACTEC 9240 and FX200; BD Biosciences) at $35^{\circ} \mathrm{C}$ for up to 5 days prior to being reported as negative. After a positive signal was obtained on the instrument, the cells were smeared and inoculated on a blood agar, and cultivated at $35^{\circ} \mathrm{C}$. These cultivated bacteria were identified with the BD Phoenix ${ }^{\mathrm{TM}}$ automated identification and susceptibility testing system (BD Biosciences).

Statistical analysis. All data were analyzed using SPSS 19.0 software (IBM Corp.). The patients' features were assessed using the median (interquartile range) for continuous variables and $\mathrm{n}(\%)$ for categorical variables. The Mann-Whitney U-test and chi-square test were used for continuous and categorical variables, respectively. A two-sided $\mathrm{P}<0.05$ was considered to indicate statistical significance.

\section{Results}

Patient characteristics at baseline. Among the 912 patients, SBP was detected in 247 (27.1\%), while the remaining 665 (72.9\%) were without SBP. The mean age of the 912 patients (681 males and 231 females) was $56.3 \pm 11.9$ years. The most general chronic underlying diseases included diabetes in 207 cases $(22.7 \%)$, high blood pressure in 190 cases $(20.8 \%)$, coronary heart disease in 15 cases $(1.6 \%)$ and alcoholic hepatitis, which was not viral hepatitis, in 260 cases $(28.5 \%)$. The most general cause of LC was viral hepatitis, which was identified in 717 patients $(78.6 \%)$, including hepatitis $\mathrm{B}$ in 139 patients (73.3\%), hepatitis C in 17 (9.4\%) and hepatitis $\mathrm{B}+\mathrm{C}$ in 3 patients (1.7\%). In addition, among the SBP patients, primary biliary hepatitis was identified in 6 patients (3.3\%), autoimmune hepatitis in 6 patients $(3.3 \%)$ and other types of hepatitis in 9 patients $(5.0 \%)$. On the other hand, among the patients without SBP, hepatitis B was present in 410 patients (68.9\%), hepatitis C in 49 patients $(9.10 \%)$ and Hepatitis B + C in 9 patients $(1.7 \%)$. Furthermore, among the patients without SBP, primary biliary hepatitis was present in 19 patients $(3.5 \%)$, autoimmune hepatitis in 16 patients $(3.0 \%)$ and other types of hepatitis in 34 patients $(6.3 \%)$. The ratios were similar between the groups with SBP and without SBP (Table I).

$S B P$ ratios in ascites patients and cirrhotic patients. As presented in Fig. 1, the SBP ratios in patients with ascites and cirrhotic increased between 2011 and 2016, with a rising trend observed between 2014 and 2015. Since 2014, as the popularity of the hospital increased, the number of patients substantially increased. Hence, the 3, 189 patients with ascites were divided into two observation groups: Group A, containing 52 SBP patients from the 765 patients with ascites admitted between 2011 and 2013, and Group B, containing 195 SBP patients from the 2, 424 patients with ascites admitted between 2014 and 2016. The patients in Group A and Group B did not distinctly differ regarding their epidemiological and clinical features. However, the laboratory results of the bacterial culture between the two groups were significantly different, i.e., they were distinctly lower in Group A than in Group B ( $\mathrm{P}=0.009$; Table II). The 912 LC patients were divided into two observation groups: Group A1, containing 52 SBP patients from the 271 patients with cirrhosis admitted between 2011 and 2013, and Group B1, containing 195 SBP patients from the 641 patients with cirrhosis admitted between 2014 and 2016. The results demonstrated that the ratio of SBP in Group B and Group B1 were higher than those in Group A and Group A1, respectively.

Laboratory results of plasma and ascitic fluid analysis in Groups 1 and 2. The results of the laboratory analyses of plasma and ascitic fluid were compared between Group 1 (SBP; 2011-2013) and Group 2 (SBP, 2014-2016). The laboratory results for Group 1 and Group 2 were not distinctly different, except for direct bilirubin [21.75 $(6.43,63.90)$ vs. $28.80(13.30,77.50), \mathrm{P}=0.034], \mathrm{C}$-reactive protein $(\mathrm{CRP})$ in the plasma $[28.63(10.78,61.88)$ vs. $44.50(18.36,87.88), \mathrm{P}=0.018]$ 
Table I. Baseline characteristics of the enrolled patients.

\begin{tabular}{lccc}
\hline Item & Total $(\mathrm{n}=912)$ & $\mathrm{SBP}+(\mathrm{n}=247)$ & SBP- $(\mathrm{n}=665)$ \\
\hline Age (years) & $56.3 \pm 11.9$ & $55.5 \pm 11.4$ & $56.6 \pm 12.1$ \\
Male gender & $681(74.7)$ & $193(78.1)$ & $488(73.4)$ \\
Diabetes & $207(22.7)$ & $52(21.1)$ & $155(23.3)$ \\
High blood pressure & $190(20.8)$ & $51(20.6)$ & $139(20.9)$ \\
Coronary heart disease & $15(1.6)$ & $5(2.0)$ & $10(1.5)$ \\
Cause & & & $194(29.2)$ \\
Alcoholic hepatitis & $260(28.5)$ & $139(56.3)$ & $410(61.7)$ \\
Hepatitis B virus & $549(60.20)$ & $17(6.9)$ & $49(7.4)$ \\
Hepatitis C virus & $66(7.24)$ & $3(1.2)$ & $9(1.4)$ \\
Hepatitis B+C virus & $12(1.32)$ & $6(2.4)$ & $19(2.9)$ \\
Primary biliary hepatitis & $25(2.74)$ & $6(2.4)$ & $16(2.4)$ \\
Autoimmune hepatitis & $22(2.41)$ & $9(3.6)$ & $34(5.1)$ \\
Other hepatitis & $43(4.71)$ & &
\end{tabular}

Values are expressed as $\mathrm{n}(\%)$ or the mean \pm standard deviation. SBP, spontaneous bacterial peritonitis.
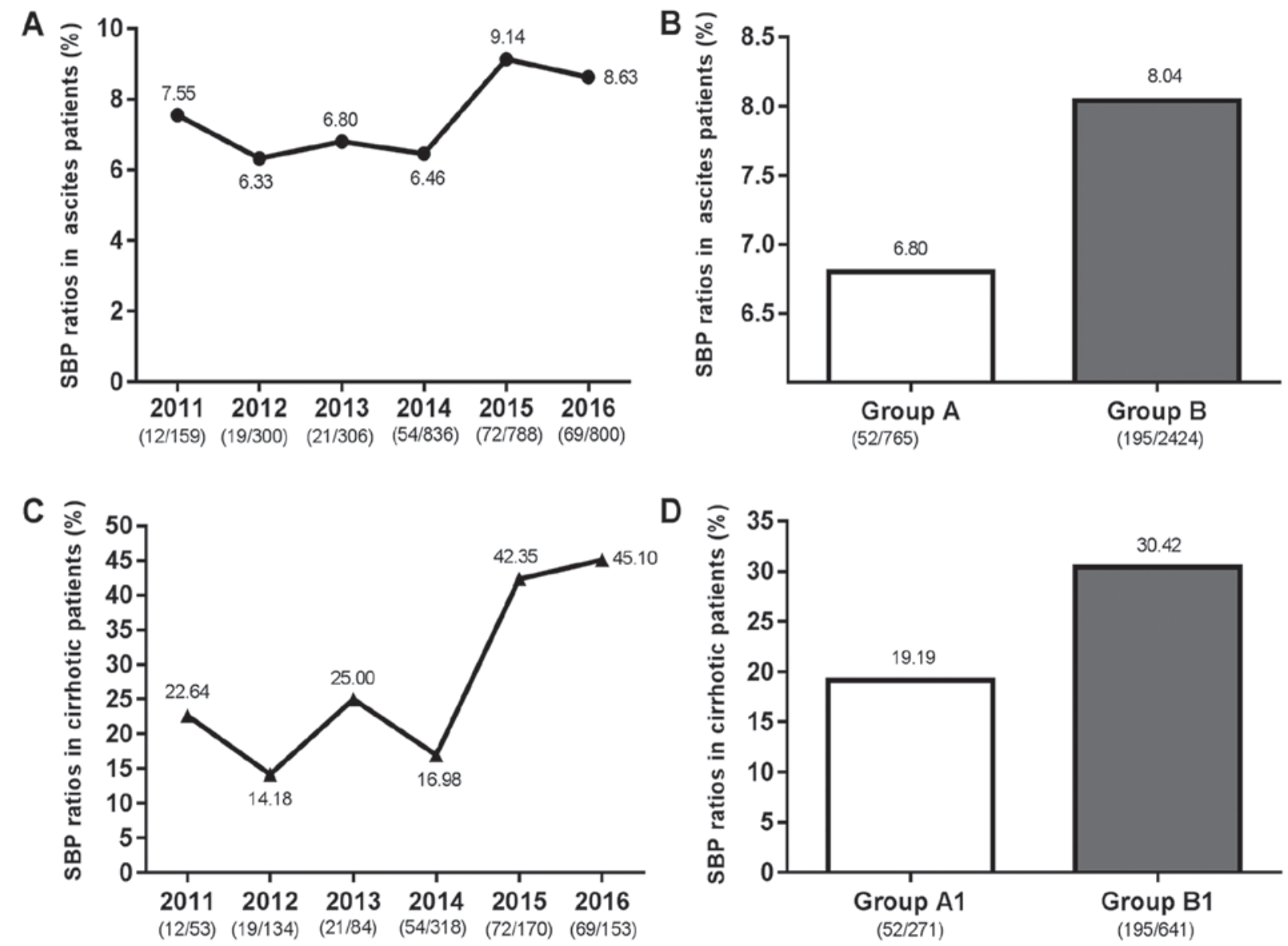

Figure 1. SBP ratios in ascites patients and cirrhotic patients. (A) SBP ratios in ascites patients from 2011 to 2016; (B) SBP ratios in ascites patients in Group A and Group B; (C) SBP ratios in cirrhotic patients from 2011 to 2016; (D) SBP ratios in cirrhotic patients in Group A1 and Group B1. Groups: A, ascites patients admitted between 2011 and 2013; B, ascites patients admitted between 2014 and 2016; A1, liver cirrhosis patients with ascites admitted between 2011 and 2013 ; B1, liver cirrhosis patients with ascites admitted between 2014 and 2016. SBP, spontaneous bacterial peritonitis.

and positive bacterial culture of ascitic fluid $[21(8.50 \%)$ vs. 118 (47.5\%), $\mathrm{P}=0.009]$; these values were distinctly lower in Group 1 compared with those in Group 2 (Table II).
Classification of total bacteria. As presented in Fig. 2, during the retrospective enrolment period, a total of 247 patients were diagnosed with SBP, and the total number of bacterial strains 
Table II. Laboratory results of patients with spontaneous bacterial peritonitis in plasma and ascitic fluid in Group 1 (n=52,21.1\%) and Group $2(\mathrm{n}=195,78.9 \%)$.

\begin{tabular}{|c|c|c|c|c|}
\hline Parameter & Group 1 & Group 2 & Reference range & P-value \\
\hline Male gender & 42 & 152 & - & 0.939 \\
\hline Age (years) & $55.00(49.00,62.75)$ & $56.00(47.00,63.00)$ & - & 0.681 \\
\hline WBC $\left(10^{9} / 1\right)$ & $7.31(4.51,10.97)$ & $8.50(4.98,13.29)$ & $4.00-10.00$ & 0.144 \\
\hline \multicolumn{5}{|l|}{ Plasma } \\
\hline Albumin (g/l) & $28.95(25.88,31.85)$ & $29.20(26.20,32.70)$ & $40.00-55.00$ & 0.542 \\
\hline Total bilirubin $(\mu \mathrm{mol} / \mathrm{l})$ & $50.60(15.43,101.78)$ & $50.60(23.80,117.70)$ & $0.00-18.80$ & 0.308 \\
\hline Creatinine $(\mu \mathrm{mol} / \mathrm{l})$ & $85.85(67.10,124.35)$ & $79.00(62.70,128.00)$ & $57.00-111.00$ & 0.814 \\
\hline Sodium (mmol/l) & $134.40(130.63,138.35)$ & $134.20(130.10,138.10)$ & $137.00-147.00$ & 0.925 \\
\hline Glucose (mmol/l) & $6.93(5.54,8.63)$ & $7.16(5.47,9.44)$ & 4.16-6.44 & 0.578 \\
\hline Urea $(\mathrm{mmol} / \mathrm{l})$ & $8.55(5.50,13.26)$ & $9.19(5.80,15.00)$ & $1.70-8.30$ & 0.512 \\
\hline Chloride (mmol/l) & $102.00(94.48,104.35)$ & $99.00(94.70,104.60)$ & $99.00-110.00$ & 0.658 \\
\hline $\operatorname{ALT}(\mathrm{U} / \mathrm{l})$ & $41.65(19.98,60.05)$ & $29.60(16.00,60.30)$ & $9.00-50.00$ & 0.145 \\
\hline AST (U/l) & $60.30(28.65,130.95)$ & $42.80(25.00,92.20)$ & $15.00-40.00$ & 0.092 \\
\hline Direct bilirubin $(\mu \mathrm{mol} / \mathrm{l})$ & $21.75(6.43,63.90)$ & $28.80(13.30,77.50)$ & $0.00-6.80$ & 0.034 \\
\hline Total protein $(\mathrm{g} / \mathrm{l})$ & $58.95(52.28,67.48)$ & $58.90(51.80,65.20)$ & $65.00-85.00$ & 0.781 \\
\hline Total bile acid $(\mu \mathrm{mol} / \mathrm{l})$ & $28.05(16.28,61.78)$ & $36.10(8.20,102.60)$ & $0.00-10.00$ & 0.784 \\
\hline Prothrombin time (sec) & $16.30(14.20,19.15)$ & $16.00(14.00,19.90)$ & $9.40-12.50$ & 0.847 \\
\hline Prothrombin time (INR) & $1.38(1.21,1.55)$ & $1.44(1.26,1.81)$ & $0.80-1.20$ & 0.136 \\
\hline $\mathrm{CRP}(\mathrm{mg} / \mathrm{l})$ & $28.63(10.78,61.88)$ & $44.50(18.36,87.88)$ & $0.00-5.00$ & 0.018 \\
\hline Ascites & & & - & \\
\hline WBC (cells/ $\mu \mathrm{l})$ & $1,771.00(450.00,3,195.00)$ & $1,515.00(600.00,6,127.00)$ & - & 0.741 \\
\hline $\mathrm{PMN}($ cells $/ \mu 1)$ & $1,077.10(279.70,2,494.00)$ & $800.00(120.12,4,262.65)$ & - & 0.931 \\
\hline Kalium (mmol/l) & $3.79(3.44,4.29)$ & $3.93(3.36,4.47)$ & - & 0.977 \\
\hline Sodium (mmol/l) & $134.60(131.30,139.00)$ & $134.30(129.80,139.40)$ & - & 0.485 \\
\hline Chloride (mmol/l) & $106.90(99.20,110.30)$ & $104.80(98.10,110.00)$ & - & 0.315 \\
\hline Glucose (mmol/l) & $7.78(6.51,8.79)$ & $7.70(6.28,9.75)$ & - & 0.538 \\
\hline Albumin $(\mathrm{g} / \mathrm{l})$ & $9.20(4.20,17.00)$ & $7.10(4.40,11.80)$ & - & 0.260 \\
\hline Positive ascitic fluid culture & $21(8.50)$ & $118(47.5)$ & - & 0.009 \\
\hline In-hospital mortality & $12(4.86)$ & $37(14.98)$ & - & 0.511 \\
\hline
\end{tabular}

Values are expressed as $\mathrm{n}(\%)$ or median (interquartile range). Groups: 1, ascites patients with liver cirrhosis and SBP admitted between 2011 and 2013; 2, ascites patients with liver cirrhosis and SBP admitted between 2014 and 2016. WBC, white blood cells; ALT, alanine aminotransferase; AST, aspartate aminotransferase; CRP, C-reactive protein; PMN, polymorphonuclear leukocytes; INR, international normalized ratio.

obtained from the positive culture of ascitic fluid was 139. In addition, the number of bacteria detected in Group 1 (21 strains) was markedly lower than that in Group 2 (118 strains). Furthermore, the rate of infection with GPB was markedly higher in Group 2 than that in Group 1 [10/21 (48\%) vs. 63/118 (53.4\%); Fig. 2B]. Over time, GPB and gram-negative bacteria (GNB) were increased, while the increase of GPB was greater than that of GNB (Fig. 2A and B).

The strains obtained from the ascitic fluid of patients during the whole term of the study (2011-2016) are presented in Fig. 2C and D. Among the bacteria in ascitic fluid, 139 species were identified, of which 66 (47.5\%) were GPB and 73 (52.5\%) were GNB. Among the GNB, Escherichia coli was the most common isolated stain (26 out of 66 cases, 39.4\%), followed by Klebsiella pneumonia (12 cases, 18.2\%), Enterobacter cloacae (7 cases, 10.6\%), Pseudomonas aeruginosa (5 cases, 7.6\%),
Acinetobacter baumannii and Citrobacter (3 cases, 4.6\%, respectively), as well as Enteroaerogen, Klebsiella acid bacteria, Aeromonas hydrophila and Pseudomonas (2 cases, $3.0 \%$, respectively), Alcaligenes and Salmonella (1 case, 1.5\%, respectively). The GPB comprised Streptococcus (17 cases, 23.3\%), as well as Enterococcus and Staphylococcus species (28 cases, $38.3 \%$, respectively).

Laboratory results of cirrhotic patients with culture-positive SBP compared between GNB and GPB. The 73 SBP patients with GPB, compared with the 66 SBP patients with GNB, were discovered to have decreased mean plasma ALT [23.5 $(15.0,56.2)$ vs. $41.1(21.2,73.1), \mathrm{P}=0.001]$ and $\mathrm{AST}[38.5$ $(24.3,75.9)$ vs. $62.0(29.3,139.9), P=0.004]$ levels, and a greater prothrombin time [international normalized ratio, $4.49(1.30,1.87)$ vs. 1.38 (1.21, 1.60), $\mathrm{P}=0.011]$. Furthermore, 
A

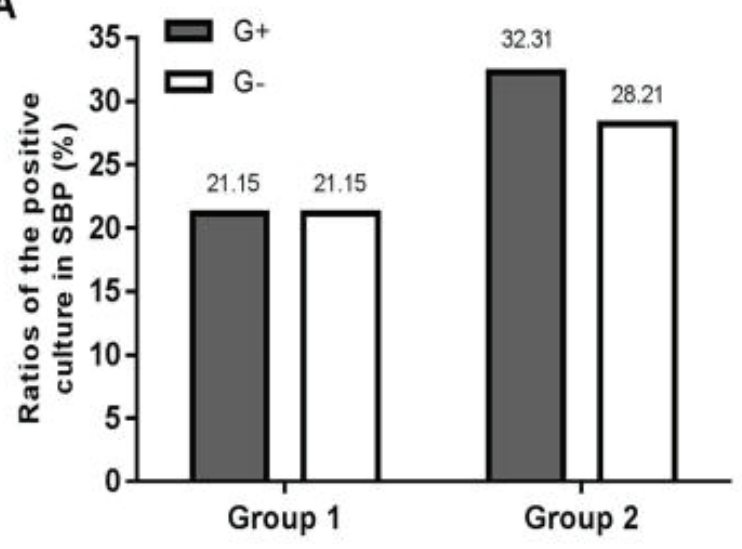

C

Gram-positive bacteria(73 strains)

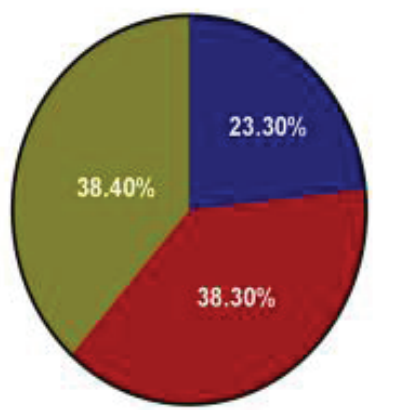

Streptococcus

Enterococcus
B

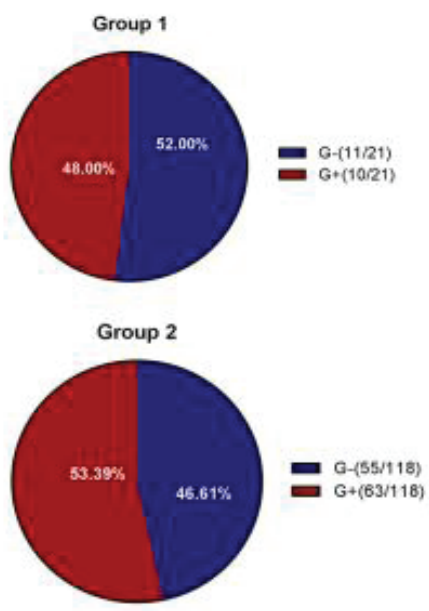

D

Staphylococcus

Gram-negative bacteria(66 strains)

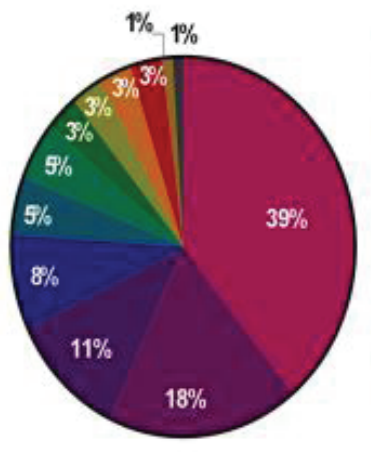

Escherichia coli

- Klebsiellapneumoniae

- Enterobacter cloacae

- Pseudmonas aeruginosa

- Acinetobacter baumannii

- Citrobacter

Enteroaerogen

$\square$ Klebsiellaacid bacteria

$\square$ Aeromonas hydrophila

Dseudmonas

Alcaligenes

Salmonella

Figure 2. Classification of total bacteria. (A) Ratios of Gram-positive bacteria and Gram-negative bacteria in the positive culture in SBP compared between Group 1 and Group 2. (B) Proportion of Gram-positive bacteria and Gram-negative bacteria compared between Group 1 and Group 2. (C) The species and distribution of Gram-positive bacteria. (D) The species and distribution of Gram-negative bacteria. Groups: 1, ascites patients with liver cirrhosis and SBP admitted between 2011 and 2013; 2, ascites patients with liver cirrhosis and SBP admitted between 2014 and 2016. G+, Gram-positive bacteria; G-, Gram-negative bacteria; SBP, spontaneous bacterial peritonitis.

SBP patients with GPB, compared with those with GNB, had an obviously lower median ascitic white blood cell count [884.0 (173.0, 6891.8) vs. 1, $973.0(937.8,3,913.0), \mathrm{P}=0.002]$, PMN [362.6 (43.2, 5, 040.0) vs. 1232.2 (498.8, 2, 557.5), $\mathrm{P}=0.001]$ and albumin $[6.20(4.15,10.20)$ vs. $8.60(4.58,16.63)$, $\mathrm{P}=0.008$; Table III].

In-hospital complications and different pathogenies compared between GNB and GPB. Comparison of the in-hospital complications and different pathogenies revealed significantly higher alcoholic hepatitis (18.18 vs. 35.62, $\mathrm{P}=0.042)$ and Splenauxe (10.61 vs. $27.40, \mathrm{P}=0.008)$, as well as lower constipation $(0.001$ vs. 9.09, $\mathrm{P}=0.020$ ) in subjects with GPB vs. GNB (Table IV).

Antibiotic resistance of $G N B$ and GPB strains. In the present study, Escherichia coli (GNB) and coagulase-negative Staphylococcus (GPB) were the major pathogens in SBP. Furthermore, 16 Escherichiacolistrains and 12 Klebsiellapneumonia strains were extended-spectrum $\beta$-lactamase-positive (Table V). The resistance rate of Staphylococcus aureus $(\mathrm{n}=8)$ and coagulase-negative Staphylococcus $(n=20)$ to penicillin (ampicillin) was $100 \%(8,20)$, while the corresponding rate for vancomycin, teicoplanin, amikacin and linezolid was $0 \%$, which was consistent with recommendations provided by the Clinical Laboratory Standards Institute (11).

\section{Discussion}

SBP is a general and severe complication of LC patients with ascites. It remains to be associated with a significant amount of mortality, in spite of recent improvements in curative approaches (12). It is generally accepted that an intestinal GNB flora, particularly Enterobacteriaceae, is the major cause of SBP (13). However, a number of studies have indicated that the proportion of GPB in SBP was increased even more than that of GNB $(2,14,15)$. Furthermore, the emergence of multidrug-resistant bacteria and the variation in the epidemiology of bacteria may lead to failure of the first-line empirical treatment program, thereby posing great challenges (16). In view of the complexity of SBP strains and the dependence on empirical treatment, the present study aimed to clarify the changes of the bacterial spectrum in SBP and drug resistance, so as to provide a reliable reference for clinical practice.

In the present study, during the observational period, the number of patients with SBP increased, and the number of 
Table III. Laboratory parameters of cirrhotic patients with culture-positive spontaneous bacterial peritonitis compared between Gram-negative bacteria and Gram-positive bacteria.

\begin{tabular}{|c|c|c|c|}
\hline Parameter & Gram-positive bacteria $(n=73)$ & Gram-negative bacteria $(n=66)$ & P-value \\
\hline WBC $\left(10^{9} / 1\right)$ & $8.07(4.80,13.1)$ & $8.49(4.85,13.15)$ & 0.633 \\
\hline \multicolumn{4}{|l|}{ Plasma } \\
\hline Albumin $(\mathrm{g} / \mathrm{l})$ & $29.3(26.2,32.2)$ & $29.0(26.2,32.5)$ & 0.600 \\
\hline Total bilirubin $(\mu \mathrm{mol} / \mathrm{l})$ & $51.8(23.9,114.2)$ & $50.7(20.3,106.8)$ & 0.351 \\
\hline Creatinine $(\mu \mathrm{mol} / \mathrm{l})$ & $87.0(62.7,131.2)$ & $77.4(64.1,119.5)$ & 0.362 \\
\hline Sodium (mmol/l) & $134.8(130.6,138.9)$ & $134.0(139.8,137.2)$ & 0.213 \\
\hline Glucose (mmol/l) & $7.25(5.34,9.45)$ & $6.94(5.54,9.19)$ & 0.606 \\
\hline Urea $(\mathrm{mmol} / \mathrm{l})$ & $9.83(6.21,15.42)$ & $8.01(5.74,13.92)$ & 0.157 \\
\hline Chloride (mmol/l) & $99.3(95.2,104.9)$ & $100.4(93.9,103.8)$ & 0.780 \\
\hline $\operatorname{ALT}(\mathrm{U} / \mathrm{l})$ & $23.5(15.0,56.2)$ & $41.1(21.2,73.1)$ & 0.001 \\
\hline AST (U/l) & $38.5(24.3,75.9)$ & $62.0(29.3,139.9)$ & 0.004 \\
\hline Direct bilirubin $(\mu \mathrm{mol} / \mathrm{l})$ & $28.9(13.2,76.1)$ & $25.0(9.5,70.6)$ & 0.450 \\
\hline Total protein $(\mathrm{g} / \mathrm{l})$ & $58.5(51.2,64.9)$ & $60.0(53.2,66.8)$ & 0.396 \\
\hline Total bile acid $(\mu \mathrm{mol} / \mathrm{l})$ & $38.4(10.0,99.7)$ & $31.5(11.8,100.1)$ & 0.873 \\
\hline Prothrombin time (sec) & $16.4(14.3,20.4)$ & $16.0(13.9,18.9)$ & 0.339 \\
\hline Prothrombin time (INR) & $4.49(1.30,1.87)$ & $1.38(1.21,1.60)$ & 0.011 \\
\hline $\mathrm{CRP}(\mathrm{mg} / \mathrm{l})$ & $47.7(21.7,85.5)$ & $43.3(20.5,80.5)$ & 0.962 \\
\hline \multicolumn{4}{|l|}{ Ascites } \\
\hline WBC (cells/ $\mu \mathrm{l})$ & $884.0(173.0,6,891.8)$ & $1973.0(937.8,3,913.0)$ & 0.002 \\
\hline $\mathrm{PMN}($ cells $/ \mu 1)$ & $362.6(43.2,5,040.0)$ & $1232.2(498.8,2,557.5)$ & 0.001 \\
\hline Kalium (mmol/l) & $3.94(3.34,4.44)$ & $3.90(3.43,4.43)$ & 0.793 \\
\hline Sodium (mmol/l) & $134.8(129.9,139.7)$ & $134.2(130.0,138.8)$ & 0.712 \\
\hline Chloride (mmol/l) & $105.6(98.9,109.8)$ & $105.7(98.3,111.0)$ & 0.903 \\
\hline Glucose (mmol/l) & $7.81(6.60,9.65)$ & $7.62(6.27,9.43)$ & 0.314 \\
\hline Albumin $(\mathrm{g} / \mathrm{l})$ & $6.20(4.15,10.20)$ & $8.60(4.58,16.63)$ & 0.008 \\
\hline
\end{tabular}

Values are expressed as the median (interquartile range). WBC, white blood cells; ALT, alanine aminotransferase; AST, aspartate aminotransferase; CRP, C-reactive protein; PMN, polymorphonuclear leukocytes; INR, international normalized ratio.

bacteria also increased over time. The proportion of GPB increased between 2014-2016 compared with 2011-2013, and was even higher than the proportion of GNB. Since the detection methods and instruments used were the same between 2011 and 2016, there should be no significant difference in detection sensitivity. These results were in coherence with several studies, which reported a high frequency of GPB infection associated with SBP (17). Through the analysis of serological and ascites indexes, it was revealed that direct bilirubin, CRP in the plasma and the positive rate of ascites culture in Group 2 were all higher than those in Group 1. This may be attributed to the clinicians paying more attention to patients with cirrhosis compared to patients with SBP, leading to an improved rate of detection.

Next, the laboratory parameters of cirrhotic patients with culture-positive SBP and their in-hospital complications, as well as the pathogeny and complications were compared between GNB and GPB. The results indicated that GPB infection was more likely to occur in alcoholic hepatitis patients, and to be associated with complications of splenauxe and constipation, while GNB infection caused more serious liver damage and severe abdominal infection. Therefore, the results of the present study suggested that clinicians should pay attention to the possibility of GPB infection in alcoholic hepatitis patients with SBP, and to consider taking measures to prevent splenauxe and constipation in SBP patients with GPB infection. In addition, for SBP patients with GNB infection, it is essential to keep a watchful eye on the occurrence of liver damage.

Furthermore, the antibiotic resistance of GPB and GNB was assessed. The results on drug sensitivity revealed that the resistance rate of GPB and GNB to penicillin (ampicillin) was $100 \%$, while the resistance rates to amikacin, imipenem, meropenem, piperacillin/tazobactam were $0 \%$ for GNB, and the resistance rates to vancomycin, teicoplanin, amikacin and linezolid were $0 \%$ for GPB. These results indicate that the antibiotics to be appliedmay in part be determined based on the bacterial strains involved in SBP in individual patients. The reported percentage of drug resistance of major pathogenic bacteria to antibiotics recommended as first-line medications by guidelines is relatively high $(10,18,19)$. This may be attributed to the imperfection of the antibiotic management 
Table IV. Comparison of in-hospital complications and different pathogenies between Gram-negative bacteria and Gram-positive bacteria.

\begin{tabular}{|c|c|c|c|}
\hline Item & Gram-positive bacteria $(n=73)$ & Gram-negative bacteria $(n=66)$ & P-value \\
\hline \multicolumn{4}{|l|}{ Pathogenies, n (\%) } \\
\hline Alcoholic hepatitis & 27 (36.99) & $13(19.70)$ & 0.042 \\
\hline Hepatitis B & $35(47.95)$ & $32(48.48)$ & 1.000 \\
\hline Hepatitis C & $3(4.11)$ & $5(7.58)$ & 1.000 \\
\hline Hepatitis B + C & $1(1.37)$ & $1(1.52)$ & 1.000 \\
\hline Primary biliary hepatitis & $0(0.00)$ & $3(4.55)$ & 1.000 \\
\hline Autoimmune hepatitis & $2(2.74)$ & $2(3.03)$ & 1.000 \\
\hline \multicolumn{4}{|l|}{ Complications, n (\%) } \\
\hline Reflux esophagitis & $11(15.07)$ & $12(18.18)$ & 0.348 \\
\hline Hepatorenal syndrome & $14(19.18)$ & $19(28.79)$ & 0.259 \\
\hline Hypoproteinemia & $58(79.45)$ & $47(71.21)$ & 0.354 \\
\hline Upper gastrointestinal hemorrhage & $16(21.92)$ & $7(10.61)$ & 0.074 \\
\hline Hepatic encephalopathy & $30(41.10)$ & $18(27.27)$ & 0.088 \\
\hline Esophagus varix & $25(34.25)$ & $18(27.27)$ & 0.278 \\
\hline Esophagus bleeding & $17(23.29)$ & $9(13.64)$ & 0.228 \\
\hline Splenauxe & $21(28.77)$ & $8(12.12)$ & 0.008 \\
\hline Spleen hyperfunction & $32(43.84)$ & $25(37.88)$ & 0.477 \\
\hline Gallstone & $11(15.07)$ & $9(13.64)$ & 0.989 \\
\hline Cholecystitis & $6(8.22)$ & $5(7.58)$ & 0.889 \\
\hline Pulmonary infection & $16(21.92)$ & $17(25.76)$ & 0.597 \\
\hline Pleural effusion & $13(17.81)$ & $15(22.73)$ & 0.472 \\
\hline Constipation & $1(1.37)$ & $7(10.61)$ & 0.020 \\
\hline Gastrohelcosis & $11(15.07)$ & $9(13.64)$ & 0.588 \\
\hline Hepatic failure & $17(23.29)$ & $17(25.76)$ & 0.590 \\
\hline Chronic renal failure & $15(20.55)$ & $10(15.15)$ & 0.410 \\
\hline Hyperkalemia & $9(12.33)$ & $9(13.64)$ & 0.819 \\
\hline Hypokalemia & $23(31.51)$ & $22(33.33)$ & 0.819 \\
\hline Hyponatremia & $7(9.59)$ & $8(12.12)$ & 0.843 \\
\hline Anemia & $30(41.10)$ & $23(34.85)$ & 0.451 \\
\hline Hemorrhagic shock & $4(5.48)$ & $2(3.03)$ & 0.802 \\
\hline Primary hepatic carcinoma & $19(26.03)$ & $17(25.76)$ & 0.971 \\
\hline Portal hypertension & $7(9.59)$ & $7(10.61)$ & 0.843 \\
\hline Metabolic acidosis & $5(6.85)$ & $4(6.06)$ & 0.851 \\
\hline
\end{tabular}

system in China. The results of the present study suggest that the use of acombination of ampicillin/sulbactam or piperacillin/tazobactam as an experiential therapy for SBP patients. In nosocomial cases, the abovementioned drugs should be combined with vancomycin, linezolid or teicoplanin, when required.

The present study has a number of limitations. First, the patients included were from a single unit (Beijing Di Tan Hospital, Capital Medical University, Beijing, China) where the occurrence of HBV associated with chronic kidney disease, LC and hepatocellular carcinoma is high. Furthermore, due to the retrospective nature of the study, a possibility for bias and imprecise data collection may exist. More comprehensive prospective studies using a larger number of cases and involving multiple units may be essential. Furthermore, more samples will be collected to validate this trend in the future.
It is imperative that physicians consider all relevant factors when diagnosing and treating patients with cirrhosis and SBP $(20,21)$.

Furthermore, SBP is a severe complication of LC, and all patients should be considered for inchoate diagnosis and curative treatment in order to lower the amount of fatalities (22). High vigilance in patients with ascites presenting with acute clinical deterioration is imperative. The present study indicated differences of the laboratory results of Groups 1 and 2, as well as in-hospital complications between patients with GPB and GNB infection. Combined use of ampicillin/sulbactam or piperacillin/tazobactamin experiential therapy is recommended. In nosocomial cases, these drugs should be combined with vancomycin, linezolid or teicoplanin when required. Therefore, it is essential to watch out for changes in respective indicatorsin plasma and ascites, as well as detect pathogens as 
Table V. Antibiotic resistance of Gram-negative and -positive bacterial strains.

A, Antibiotic resistance of Gram-negative bacterial strains

\begin{tabular}{|c|c|c|c|}
\hline \multirow[b]{2}{*}{ Antibiotic, n (\%) } & \multicolumn{2}{|c|}{ Escherichia coli $(\mathrm{n}=26)$} & \multirow{2}{*}{$\begin{array}{l}\begin{array}{l}\text { Klebsiella pneumoniae } \\
(\mathrm{n}=12)\end{array} \\
\text { ESBL-positive }(\mathrm{n}=16)\end{array}$} \\
\hline & ESBL-positive $(\mathrm{n}=16)$ & ESBL-negative $(n=10)$ & \\
\hline Ampicillin & $16(100.00)$ & $10(100.00)$ & $12(75.00)$ \\
\hline Ticarcillin/clavulanic acid & $3(18.75)$ & $0(0.00)$ & $1(6.25)$ \\
\hline Amikacin & $0(0.00)$ & $0(0.00)$ & $1(6.25)$ \\
\hline Aztreonam & $7(43.75)$ & $0(0.00)$ & $2(12.50)$ \\
\hline Chloromycetin & $8(50.00)$ & $0(0.00)$ & $1(6.25)$ \\
\hline Cefazidime & $3(18.75)$ & $0(0.00)$ & $2(12.50)$ \\
\hline Ciprofloxacin & $13(81.25)$ & $2(20.00)$ & $2(12.50)$ \\
\hline Cefotaxime & $11(68.75)$ & $0(0.00)$ & $2(12.50)$ \\
\hline Cephazolin & $15(93.75)$ & $1(10.00)$ & $2(12.50)$ \\
\hline Cefepime & $6(37.50)$ & $0(0.00)$ & $2(12.50)$ \\
\hline Gentamicin & $7(43.75)$ & $0(0.00)$ & $1(6.25)$ \\
\hline Imipenem & $0(0.00)$ & $0(0.00)$ & $1(6.25)$ \\
\hline Levofloxacin & $13(81.25)$ & $2(20.00)$ & $2(12.50)$ \\
\hline Meropenem & $0(0.00)$ & $0(0.00)$ & $1(6.25)$ \\
\hline Piperacillin & $16(100.00)$ & $0(0.00)$ & $3(18.75)$ \\
\hline Ampicillin/sulbactam & $5(31.25)$ & $0(0.00)$ & $2(12.50)$ \\
\hline $\mathrm{SMZ}$ & $12(75.00)$ & $0(0.00)$ & $3(18.75)$ \\
\hline Acheomycin & $14(87.50)$ & $1(10.00)$ & $3(18.75)$ \\
\hline Piperacillin/tazobactam & $2(12.50)$ & $0(0.00)$ & $1(6.25)$ \\
\hline
\end{tabular}

B, Antibiotic resistance of Gram-positive bacterial strains

\begin{tabular}{|c|c|c|}
\hline Antibiotic, n (\%) & Staphylococcus aureus $(\mathrm{n}=8)$ & Coagulase-negative Staphylococcus $(\mathrm{n}=20)$ \\
\hline Ampicillin & $8(100.00)$ & $20(100.00)$ \\
\hline Ticarcillin/clavulanic acid & $1(12.50)$ & $18(90.00)$ \\
\hline Amikacin & $0(0.00)$ & $0(0.00)$ \\
\hline Clindamycin & $1(12.50)$ & $6(30.00)$ \\
\hline Ciprofloxacin & $0(0.00)$ & $10(50.00)$ \\
\hline Erythromycin & $3(37.50)$ & $18(90.00)$ \\
\hline Macrodantin & $0(0.00)$ & $19(95.00)$ \\
\hline Cefoxitin & $1(12.50)$ & $20(100.00)$ \\
\hline Gentamicin & $0(0.00)$ & $9(45.00)$ \\
\hline Linezolid & $0(0.00)$ & $1(5.00)$ \\
\hline Tobramycin & $1(12.50)$ & $9(45.00)$ \\
\hline Oxacillin & $1(12.50)$ & $18(90.00)$ \\
\hline Penicillin & $6(75.00)$ & $20(100.00)$ \\
\hline Rifampicin & $0(0.00)$ & $16(80.00)$ \\
\hline SMZ & $1(12.50)$ & $14(70.00)$ \\
\hline Quinupristin/dalfopristin & $0(0.00)$ & $0(0.00)$ \\
\hline Tetracycline & $0(0.00)$ & $6(30.00)$ \\
\hline Teicoplanin & $0(0.00)$ & $0(0.00)$ \\
\hline Vancomycin & $0(0.00)$ & $0(0.00)$ \\
\hline
\end{tabular}

SMZ, sulfamethoxazole; ESBL, extended spectrum beta-lactamases. 
early as possible to ensure for timely diagnosis and treatment of SBP.

\section{Acknowledgements}

Not applicable.

\section{Funding}

The present study was supported by a grant from the Beijing Key Laboratory of Emerging Infectious Diseases Project (grant no. DTKF201702).

\section{Availability of data and materials}

The dataset supporting the results of the present study are included in the article.

\section{Authors' contributions}

JG and YW contributed to the conception of the study and prepared the manuscript, as well as overall supervision. JS revised the manuscript. JG and HW collected he data. SL, HC and JL analyzed the data. All authors read and approved the final manuscript.

\section{Ethics approval and consent to participate}

All of the patients' data were collected retrospectively from their electronic health records. The present study was approved by the Ethics Committee of the Beijing Di Tan Hospital (Beijing, China) and was in accordance with the 1975 Declaration of Helsinki.

\section{Patient consent for publication}

Not applicable.

\section{Competing interests}

The authors declare that they have no competing interests.

\section{References}

1. Tsochatzis EA, Bosch $\mathrm{J}$ and Burroughs AK: Liver cirrhosis. Lancet 383: 1749-1761, 2014.

2. Fiore M, Maraolo AE, Gentile I, Borgia G, Leone S, Sansone P, Passavanti MB, Aurilio C and Pace MC: Current concepts and future strategies in the antimicrobial therapy of emerging Gram-positive spontaneous bacterial peritonitis. World J Hepatol 9: 1166-1175, 2017.

3. Cui Y and Jia J: Update on epidemiology of hepatitis B and C in China. J Gastroenterol Hepatol 28 (Suppl 1): S7-S10, 2013.

4. Enomoto H, Inoue S, Matsuhisa A and Nishiguchi S: Diagnosis of spontaneous bacterial peritonitis and an in situ hybridization approach to detect an 'unidentified' pathogen. Int J Hepatol 2014: 634617, 2014.
5. Kim JH, Jeon YD, Jung IY, Ahn MY, Ahn HW, Ahn JY, Ku NS, Han SH, Choi JY, Ahn SH, et al: Predictive factors of spontaneous bacterial peritonitis caused by gram-positive bacteria in patients with cirrhosis. Medicine (Baltimore) 95: e3489, 2016.

6. Paul K, Kaur J and Kazal HL: To study the incidence, predictive factors and clinical outcome of spontaneous bacterial peritonitis in patients of cirrhosis with ascites. J Clin Diagn Res 9: OC09-OC12, 2015.

7. Yan $\mathrm{K}$ and Garcia-Tsao G: Novel prevention strategies for bacterial infections in cirrhosis. Expert Opin Pharmacother 17: 689-701, 2016.

8. Fukui H: Gut Microbiome-based therapeutics in liver cirrhosis: Basic consideration for the next step. J Clin Transl Hepatol 5: 249-260, 2017.

9. Runyon BA: Management of adult patients with ascites due to cirrhosis: Update 2012. American Association for the Study of Liver Diseases, 2012. https://www.aasld.org/sites/default/ files/guideline_documents/adultascitesenhanced.pdf. Accessed May 6, 2012.

10. European Association for the Study of the Liver: EASL clinical practice guidelines on the management of ascites, spontaneous bacterial peritonitis, and hepatorenal syndrome in cirrhosis. J Hepatol 53: 397-417, 2010.

11. Clinical and Laboratory Standards Institute (CLSI): Reference Method for Broth Dilution Antifungal Susceptibility Testing of Yeasts. 4th edition. CLSI standard M27. CLSI, Wayne, PA, 2017.

12. Bal CK, Daman R and Bhatia V: Predictors of fifty days in-hospital mortality in decompensated cirrhosis patients with spontaneous bacterial peritonitis. World J Hepatol 8: 566-572, 2016.

13. Wong F: Acute kidney injury in liver cirrhosis: New definition and application. Clin Mol Hepatol 22: 415-422, 2016.

14. Cholongitas E, Papatheodoridis GV, Lahanas A, Xanthaki A, Kontou-Kastellanou $\mathrm{C}$ and Archimandritis AJ: Increasing frequency of Gram-positive bacteria in spontaneous bacterial peritonitis. Liver Int 25: 57-61, 2005.

15. Yang Y, Li L, Qu C, Zeng B, Liang S, Luo Z, Wang X and Zhong C: Diagnostic accuracy of serum procalcitonin for spontaneous bacterial peritonitis due to end-stage liver disease: A Meta-analysis. Medicine (Baltimore) 94: e2077, 2015.

16. de Mattos AA, Costabeber AM, Lionco LC and Tovo CV: Multi-resistant bacteria in spontaneous bacterial peritonitis: A new step in management? World J Gastroenterol 20: 14079-14086, 2014.

17. Hatami B, Ashtari S, Sharifian A, Rahmani Seraji H, Khalili E, Hatami Y and Zali MR: Changing the cause of liver cirrhosis from hepatitis B virus to fatty liver in Iranian patients. Gastroenterol Hepatol Bed Bench 10 (Suppl): S20-S26, 2017.

18. Li YT, Yu CB, Huang JR, Qin ZJ and Li LJ: Pathogen profile and drug resistance analysis of spontaneous peritonitis in cirrhotic patients. World J Gastroenterol 21: 10409-10417, 2015.

19. Xie Y, Tu B, Zhang X, Bi J, Shi L, Zhao P, Chen W, Liu S, Xu D and Qin E: Investigation on outcomes and bacterial distributions of liver cirrhosis patients with gram-negative bacterial bloodstream infection. Oncotarget 9: 3980-3995, 2018.

20. Kim T, Hong SI, Park SY, Jung J, Chong YP, Kim SH, Lee SO, Kim YS, Woo JH, Lim YS, et al: Clinical features and outcomes of spontaneous bacterial peritonitis caused by streptococcus pneumoniae: A matched Case-control study. Medicine (Baltimore) 95: e3796, 2016.

21. Acevedo J: Multiresistant bacterial infections in liver cirrhosis: Clinical impact and new empirical antibiotic treatment policies. World J Hepatol 7: 916-921, 2015.

22. Karkmann K, Piecha F, Runzi AC, Schulz L, von Wulffen M, Benten D, Kluwe J and Wege H: Management of compensated liver cirrhosis 2018-Evidence based prophylactic measures. Z Gastroenterol 56: 55-69, 2018 (In German).

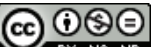

This work is licensed under a Creative Commons Attribution-NonCommercial-NoDerivatives 4.0 International (CC BY-NC-ND 4.0) License. 